\title{
Application Monitoring Design of Water Tank Volume and Clarity System Using LabView NI MYRIO
}

\author{
Erwin Nur Diansyah ${ }^{* 1}$, M. Chasrun Hasani ${ }^{2}$, Amrul Faruq ${ }^{3}$ \\ 1,2,3 Universitas Muhammadiyah Malang \\ erwindians@gmail.com*
}

\begin{abstract}
A traditional controlling and measuring system both in home industry and factory have many constraints especially in the field of quality and efficiency. Operators have to control and monitor while the tank is in the water filling mode. Consequently, an effective system is needed to increase the ease in industry operation. In this work, an application design of water volume in tank and clarity system has presented using RF04 ultrasonic sensor to detect water level; furthermore, a turbidity sensor was also employed to detect water clarity. Both of them were controlled by National Instrument (NI) myRIO-1900. NI myRIO was used in this work as a controller having automatic on/off relay module employed to the water tank and integrated with a personal computer as human machine interface system (HMI). NI LabView software used as HMI in this work was also connected to Wi-Fi module to establish a remote monitoring role. As a result, the simulation shows that water level can be measured utilizing ultrasonic sensor as well as turbidity sensor detection for water clarity.
\end{abstract}

Keywords: Tank Water Monitoring, SRF04 Sensor, Turbidity Sensor, Water Clarity, NI myRIO

\section{Introduction}

Controlling and measuring functions in home industry or factory environment through conventional system provide many limitations especially in product quality and time efficiency. Controlling water level in tanks by the operators is commonly executed and recorded manually [1]. This similar practice is also implemented in measuring the water level in tanks. The operators perform a manual daily basis record using books.

Operational system for measuring water level in tanks and water clarity as previously mentioned is not efficient. These conventional procedures frequently trigger some problems to the field operators having few personnel needed to manage a lot of tanks. Users employing manual system can cause considerable problems as well as production disruption, leading to some serious drawbacks. Therefore, utilizing the right technology is imperative, as well as providing effortless and effective operations [2] [3]. From the prior description and existing constraints, automation technology devices designed to help alleviate performance for officers to control water volume in tanks and water clarity using remote connection to facilitate the operations of industrial plants are highly necessary. These devices will employ a simulation tool monitoring system designed to measure water level and water clarity in tanks using ultrasonic and turbidity sensors through software module with LabVIEW controlling NI myRIO-1900 as the solution [4].

Thus, the system is able to monitor the water volume and water clarity automatically using the network wireless connection. Moreover, this system can also be able to display the monitoring results on a laptop or a personal computer via LabView software with NI controller MyRio-1900 [5][6]. This work presents the designing of water level and clarity monitoring system in tanks, developed from the existing system architecture, monitoring water volume using ultrasonic sensor based on AVR microcontroller. The previous research supports this project on exemplifying the latest tool development [7][8].

\section{Research Method}

This chapter describes the design and hardware manufacturing utilized by a software that will be used to support the overall system. The hardware has some parts connected to the system [9][10] while the software will serve as an intermediary between a computer and the hardware.

Nurdiansyah, E., Hasani, C., \& Faruq, A. (2017). Application Monitoring Design of Water Tank Volume and Clarity System Using LabView NI MYRIO. Kinetik : Game Technology, Information System, Computer Network, Computing, Electronics, and Control, 2(4). doi:http://dx.doi.org/10.22219/kinetik.v2i4.206

Paper submitted on April 29, 2017; Revision on June 07, 2017; Received August 17, 2017 


\subsection{The Hardware Circuit Block Diagram}

Figure 1 illustrates a block diagram of the monitoring tool design system for water volume in tanks and water clarity using LabView software controlled with myRIO. Moreover, a wireless connection is also embedded. At the beginning of the process, the design was generated by building a prototype tank made in accordance to the measurement of the degradation by a distance detection sensor. It will be monitored using SRF04 Ultrasonic sensors which can detect water in the tank and will read the distance frequency so that it can be displayed in LabView. Afterwards, designated points will be specified, addressing the minimum and maximum water conditions serving as a detection signal delivery controlling relay module for turning on/off water pump or water automatic charging control with NI myRIO.

GE Turbidity sensor was used to detect the water clarity level. This mechanism will able to show the water tank condition through indicator on the front panel. All processes from this sensor detector were received by MyRio and will be controlled by LabView software which was connected wirelessly. The software had been already programmed and created in module NI myRIO-1900, being capable to execute remote control and monitor as well as wirelessly sending the results from signal detection sensors. A programming was needed on a PC as a media controller being capable of monitoring activities that constitutes a means for the operator to monitor the water volume and water clarity in the prototype tank. The interactions form all sensors will present appropriate monitoring information in the form of a display condition of the water in the tank using LabView software. The mechanical design of water tank and monitoring tool for water volume and water clarity is illustrated in Figure 2. Moreover, Table 1 presents the design and manufacture of mechanical system for water volume monitoring prototype based on LabView controlled by NI myRIO-1900.

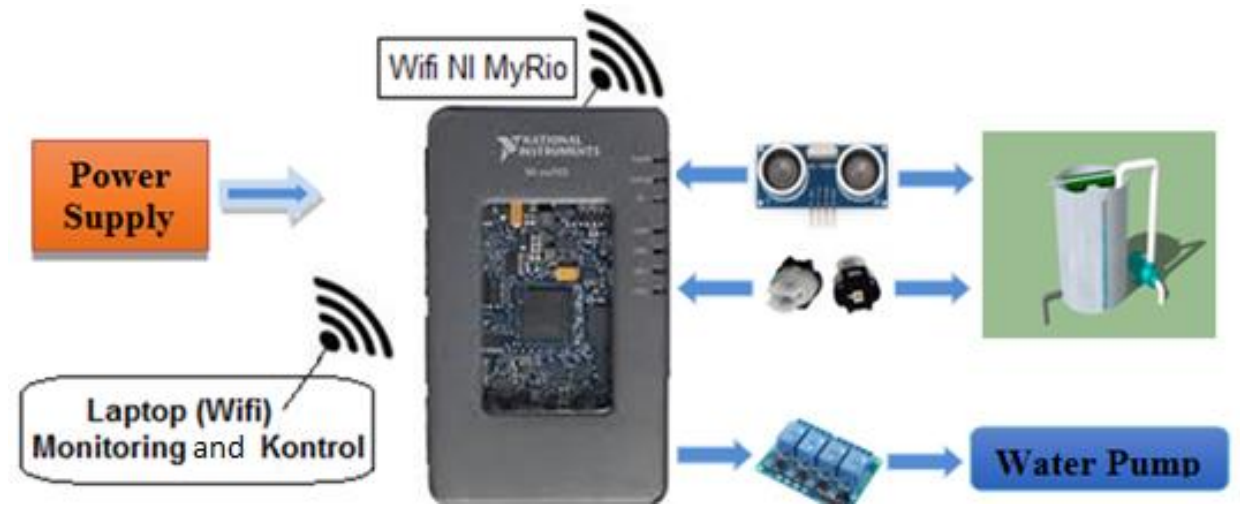

Figure 1. Hardware Circuit Block Diagram

Table 1. Mechanical Design of Electronic Map

\begin{tabular}{|c|c|c|}
\hline No & $\begin{array}{l}\text { Mechanical } \\
\text { Design }\end{array}$ & Description \\
\hline 1 & Prototype Tank & $\begin{array}{ll}\text { - } & \text { Tube-shaped iron plates } \\
\text { - } & \text { Height } 60 \mathrm{~cm} \times \text { width } 40 \mathrm{~cm} .\end{array}$ \\
\hline 2 & Poles & $\begin{array}{l}\text { - } \quad \text { Iron plate Length } 40 \mathrm{~cm} \times \text { thick } 0.3 \mathrm{~cm} \\
\text { - } \quad \text { As the mounting foothold of the sensor }\end{array}$ \\
\hline 3 & $\begin{array}{l}\text { Ultrasonic Sensor } \\
\text { SRF } 04\end{array}$ & - Water detection information \\
\hline 4 & Turbidity Sensor & $\begin{array}{ll}\text { - } & \text { Water turbidity sensor information } \\
\text { - } & \text { Remote controller }\end{array}$ \\
\hline 5 & NI myRIO-1900 & $\begin{array}{ll}\text { - } & \text { Input and output interface } \\
\text { - } & \text { IC field programmable gate array and real time system. }\end{array}$ \\
\hline 6 & $\begin{array}{l}\text { Personal } \\
\text { Computer }\end{array}$ & $\begin{array}{l}\text { - } \quad \text { Monitoring tool } \\
\text { - } \quad \text { INTOUCH wireless }\end{array}$ \\
\hline 7 & $\begin{array}{l}\text { The Relay } \\
\text { Module }\end{array}$ & - $\quad$ Automatic controller water pump \\
\hline 8 & Water Pump & _ $\quad$ Time setting of filling water level conditions \\
\hline
\end{tabular}

KINETIK Vol. 2, No. 4, November 2017: 309-318 


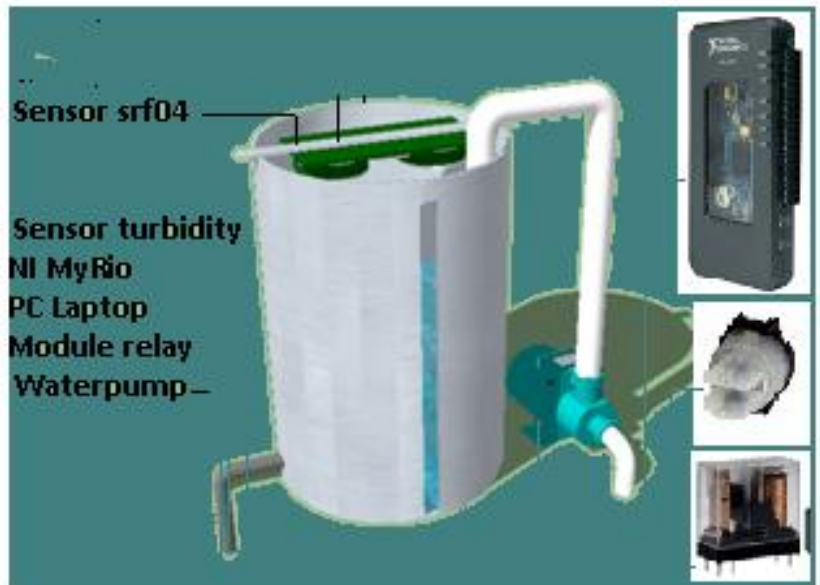

Figure 2. Mechanical Design of Water Tank

\subsection{Design of NI myRIO Controlled with Wi-Fi Embedded Module}

$\mathrm{NI}$ myRIO toolkit embedded in 1900 series was used as wireless connection in this work. The configuration allows connections of maximum 6 clients as default by the MyRio module. However, there was only one connection setting assigned to remotely connect with a laptop or a personal computer. Figure 5 shows the configuration setting menu on NI myRIO 1900 series.

\subsection{Hardware Input Circuit}

Figure 3 shows the configuration design interface utilizing ultrasonic SRF 04 with $\mathrm{NI}$ myRIO controller, connected to MXP A pin connector. In addition, Figure 4 presents the configuration design of turbidity sensor connected to MXP B pin connector. The ultrasonic and turbidity sensor have 4 inputs and 3 inputs respectively as illustrated in Table 2 and Table 3.

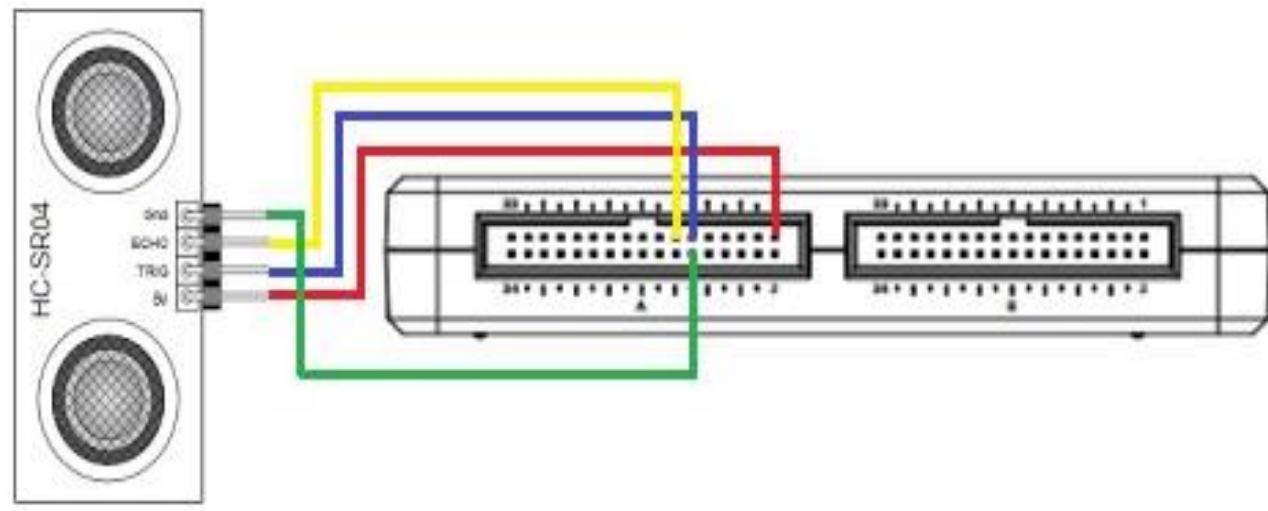

Figure 3. Hardware Input Circuit for Ultrasonic Sensor SRF04

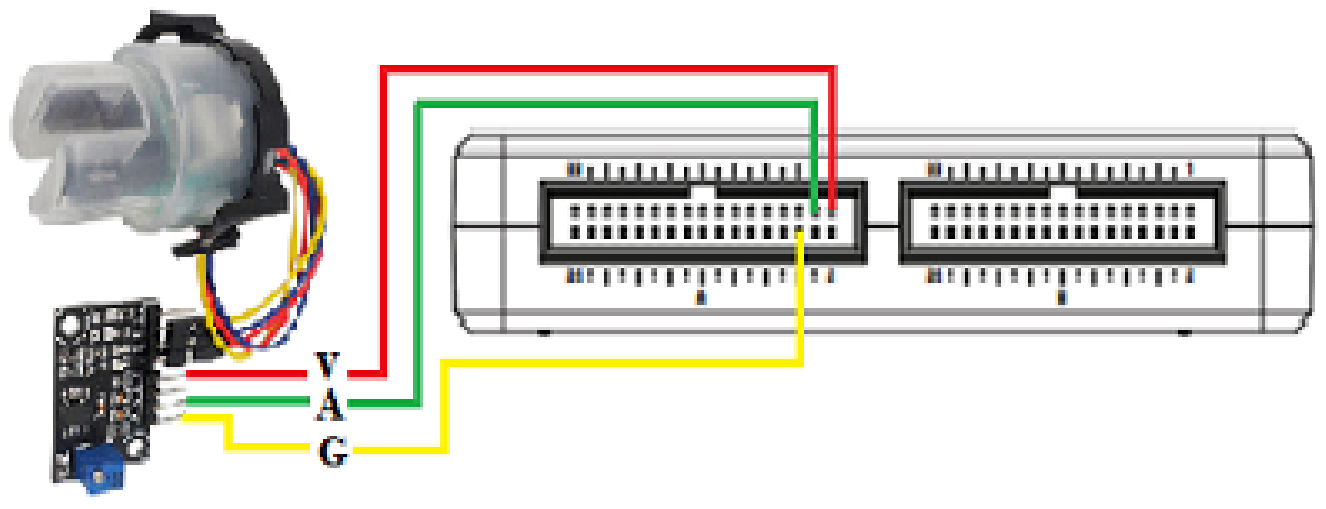

Figure 4. Hardware Input Circuit for Turbidity Sensor 
Table 2. Input Pin Configuration of Ultrasonic Sensor SRF04

\begin{tabular}{lll} 
No & Pin Sensor & \\
\hline 1 & VCC & MXP connector A on pin 1 $+5 \mathrm{~V}$ digital input. \\
2 & Trigger & MXP connector A on digital input pin 11. \\
3 & Echo & MXP connector A on pin 13 digital input \\
4 & Ground & MXP connector A on digital ground pin 12. \\
\hline
\end{tabular}

Table 3. Pin Configuration Input of Turbidity Sensor

\begin{tabular}{lll}
\hline No & Pin Sensor & \\
\hline 1 & VCC & MXP connector B on pin 1+5V digital input. \\
2 & A & MXP connector B on digital input pin 3. \\
3 & Ground & MXP connector B on digital ground pin 6. \\
\hline
\end{tabular}

\subsection{Hardware Output Circuit}

Figure 5 depicts the input of relay module is connected to $\mathrm{NI}$ myRIO. Meanwhile, the output is connected to the input voltage source of water pump. Table 4, additionally, describes the relay module interface to the output of $\mathrm{NI}$ myRIO controller as water pump input source.

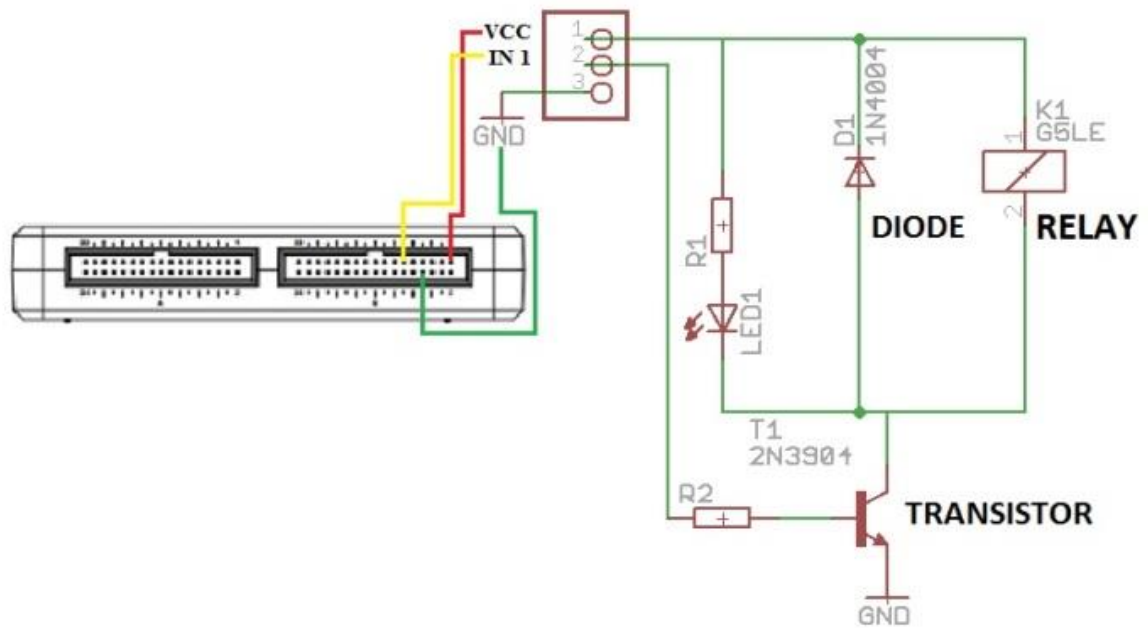

Figure 5. Hardware Output Circuit for Relay Module

Table 4. Hardware Output Pin Configuration

\begin{tabular}{lll}
\hline No & Pin Relay Module & \multicolumn{1}{c}{ Pin NI myRIO-1900 } \\
\hline 1 & VCC & MXP connector C on pin 20 +5 V digital input. \\
2 & IN & MXP connector C on the pin 18 digital PWM input \\
3 & Ground & $7 / 1$. \\
\hline
\end{tabular}

\subsection{Software Design}

This project employs software designing for monitoring water tank volume and water clarity by utilizing LabView Software. The flowchart for software design is addressed in Figure 6. The initial design of each sensor used output as relay module. Afterwards, LabView was programmed with NI myRIO 1900.

Initially, the project started with designing sensors followed by mounting output through sensor relay module. This sensor was then controlled by MyRio programmed on FPGA using a while loop in data grouping.

Designing $\mathrm{NI}$ myRIO-1900 in real time was the following step to display the process monitoring via a laptop from real-time sensors and relay module as input water pump.

\section{Results and Discussion}

LabView software will display the data transmitted from the transmitter and emitter sensor. The data showed water level in tank so that users were able to monitor water tank 
condition in real-time. This application was controlled by NI myRIO 1900 series. The application front panel view is depicted in Figure 7. The specified value of water tank level was also presented. Meanwhile, Table 5 illustrates the testing result of ultrasonic SRF04 sensor controlled by NI myRIO.

In Table 5, SRF04 ultrasonic sensor detects the water surface in the tank from the base of tank, a scale of 0 to 60 as the scale limit over the surface of the tank. This testing was executed by comparing the measurement altitude in detection censor with manual measurement using measuring meter. The calculation error of RMS (Root Mean Square) was implemented in finding the error detection value in measuring water level in the tank, having total value gap of water height, in example $7.3 \mathrm{~cm}$.

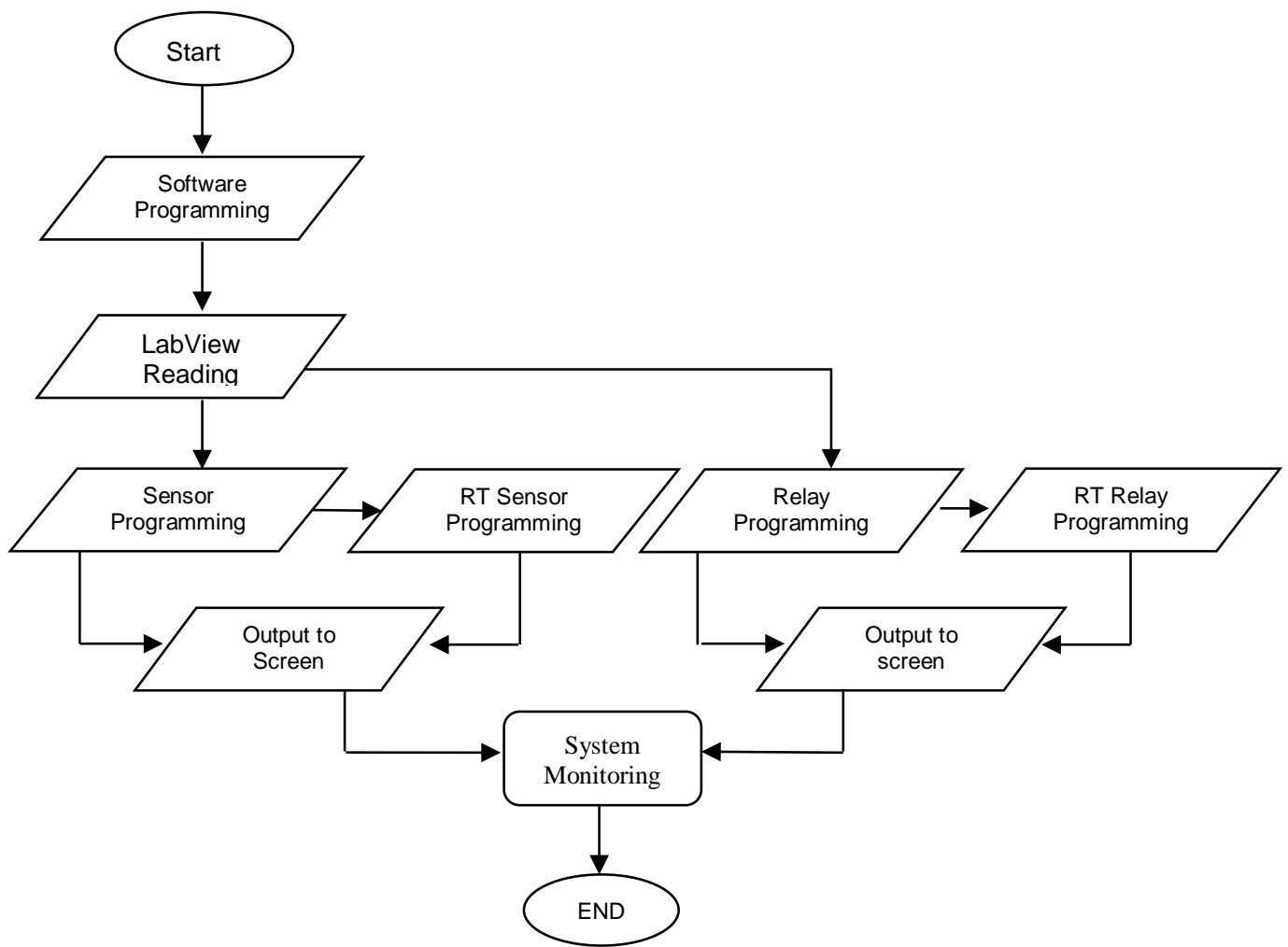

Figure 6. Software Design Flowchart

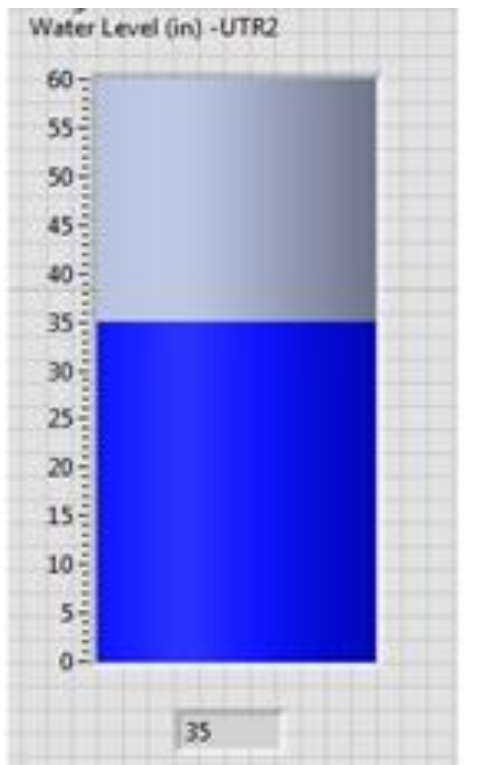

Figure 7. Front Panel View of Water Level Monitoring by LabView 


\begin{tabular}{ccccc}
\multicolumn{5}{c}{ Table 5. Testing Results of Ultrasonic Sensor SRF04 } \\
\hline No. & $\begin{array}{c}\text { 0-60 Scale Display } \\
(\mathrm{cm}) \text { in LabView }\end{array}$ & $\begin{array}{c}\text { Manual Height } \\
\text { Measurement }(\mathrm{cm})\end{array}$ & $\begin{array}{c}\text { Error Value } \\
(\mathrm{RMS}) \\
\text { Delta Value }\end{array}$ & $\begin{array}{c}\text { Ultrasonic } \\
\text { Sensor } \\
\text { Indicator }\end{array}$ \\
\hline 1 & 0 & 0 & 0 & 0 \\
2 & 5 & 5.3 & 0.3 & 395 \\
3 & 10 & 10.3 & 0.3 & 690 \\
4 & 15 & 15.4 & 0.4 & 985 \\
5 & 20 & 20.4 & 0.4 & 1280 \\
6 & 25 & 25.5 & 0.5 & 1575 \\
7 & 30 & 30.3 & 0.3 & 1870 \\
8 & 35 & 35.4 & 0.4 & 2165 \\
9 & 40 & 40.5 & 0.5 & 2460 \\
10 & 45 & 46 & 1 & 2755 \\
11 & 50 & 51.5 & 1.5 & 3150 \\
12 & 55 & 56 & 1 & 3550 \\
13 & 60 & 60.7 & 0.7 & 3995 \\
\hline \multicolumn{7}{l}{ Total Value of Measurement Difference } \\
Total Value of RMS Error
\end{tabular}

\subsection{The Testing Results of Turbidity Sensor}

From the testing that was completed in two stages, the measurements both in turbid and clear water condition analyzed on a LabView 2016 displayed the data from the reading gained from turbidity sensors against water conditions in the prototype tank and real-time monitoring of water turbidity via LabView software. Figure 8 shows the results of turbidity testing displayed in the monitor view.

Figure 8 (a) illustrates the testing of condition monitoring in clear water detection using sample water from mineral bottled water. The testing results shows rating indicator number of 3385 and is displayed as CRYSTAL CLEAR information label on LabView. Figure 8 (b) depicts the testing of condition monitoring in turbid water detection using sample water from nearby rice field. The testing results indicate value of 3273 and is displayed as TURBID on LabView. The following table presents the testing results of water turbidity sensors applied in the prototype tank.

Table 6 informs a test note reporting water turbidity sensors being able to detect the water clarity level in the tank. It can be concluded that the more turbid of water condition is, the smaller is the value detected from sensor displaying TURBID on LabView.

\subsection{Testing the Relay Module}

Another testing is completed by providing value logic of high or low output from NI myRIO. Figure 9 shows LabView monitoring indicators of the relay module and levels of condition being high or low.

Figure 9 also illustrates the existing HIGH voltage logic from NI myRIO indicating 5 volts and at a time showing the logic of LOW indicating 0 Volts. A series of relay were activated when given a logic LOW and was OFF when given a logic of $\mathrm{HIGH}$.

The test results can be recognized in Table 7, relaying module conditions of $\mathrm{ON}$ if water conditions were detected by the ultrasonic sensor SRF04 indicating LOW and will be OFF when the conditions of the water height detected by SRF04 ultrasonic sensor showed condition of $\mathrm{HIGH}$. HIGH and LOW conditions were specified in the LabView software through ultrasonic sensor indicator SRF04 when detecting high surface water.

\subsection{Testing the Water Pump Controller Circuit}

This test described a test of monitoring water levels with the output water pump control module by the control relay through NI myRIO. Thus, all processes are displayed on the LabView software accessed on a laptop. Figure 10 displays all monitoring processes on LabView system monitoring the water height and water clarity.

In Figure 10, the process, at the same time, is able to monitor the condition of the water height in the tank directly ranging from minimum, medium and maximum levels. Therefore, different water conditions can be automatically monitored by utilizing the water pump relay from a laptop showing different water pump conditions, ON or OFF.

KINETIK Vol. 2, No. 4, November 2017: 309-318 


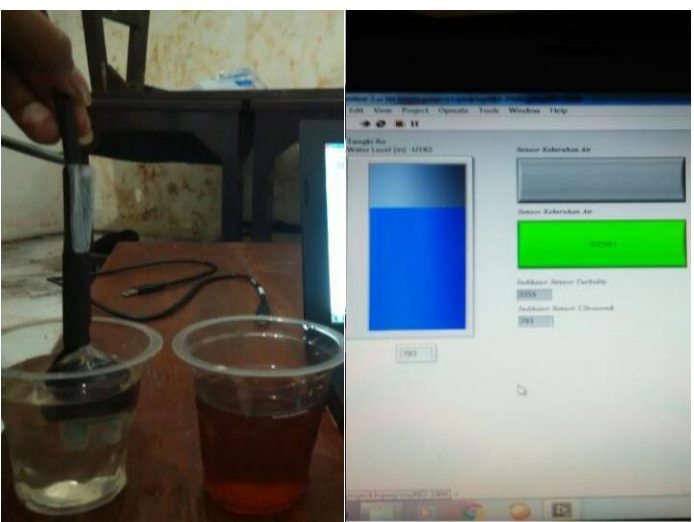

(a)

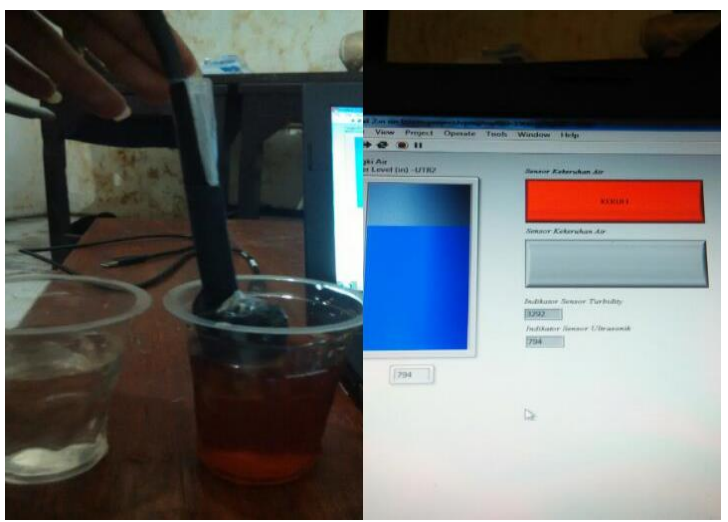

(b)

Figure 8. (a) Monitoring in Clear Wate (b) Monitoring in Turbin Water

Table 6. Testing Results of Turbidity Sensor

\begin{tabular}{|c|c|c|c|c|}
\hline \multirow{2}{*}{ No } & \multirow{2}{*}{ Types of Water Tested } & \multirow{2}{*}{$\begin{array}{l}\text { The Indicator Value } \\
\text { of Turbidity Sensor }\end{array}$} & \multicolumn{2}{|c|}{ Category } \\
\hline & & & Crystal Clear & Turbid \\
\hline 1 & Water TAPS & 3361 & $\checkmark$ & \\
\hline 2 & Bottled Mineral Water & 3385 & $\checkmark$ & \\
\hline 3 & $\begin{array}{l}\text { Water Boiled with Temperature } \\
100 \cong \mathrm{C}\end{array}$ & 3359 & $\checkmark$ & \\
\hline 4 & River Water & 3293 & & $\checkmark$ \\
\hline 5 & Rice Field Water & 3273 & & $\checkmark$ \\
\hline 6 & Waste Water & 3215 & & $\checkmark$ \\
\hline
\end{tabular}

\section{error out}

status
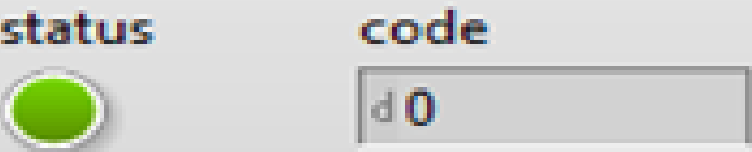

source

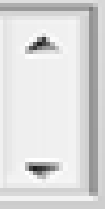

\section{relay water pump ndicator}

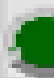

Figure 9. Relay Module Monitoring

Table 7. Testing Results of Relay Module

\begin{tabular}{ccc}
\hline No & NI myRIO Output & Indicator Relay Module \\
\hline 1 & HIGH & OFF \\
2 & LOW & ON \\
\hline
\end{tabular}




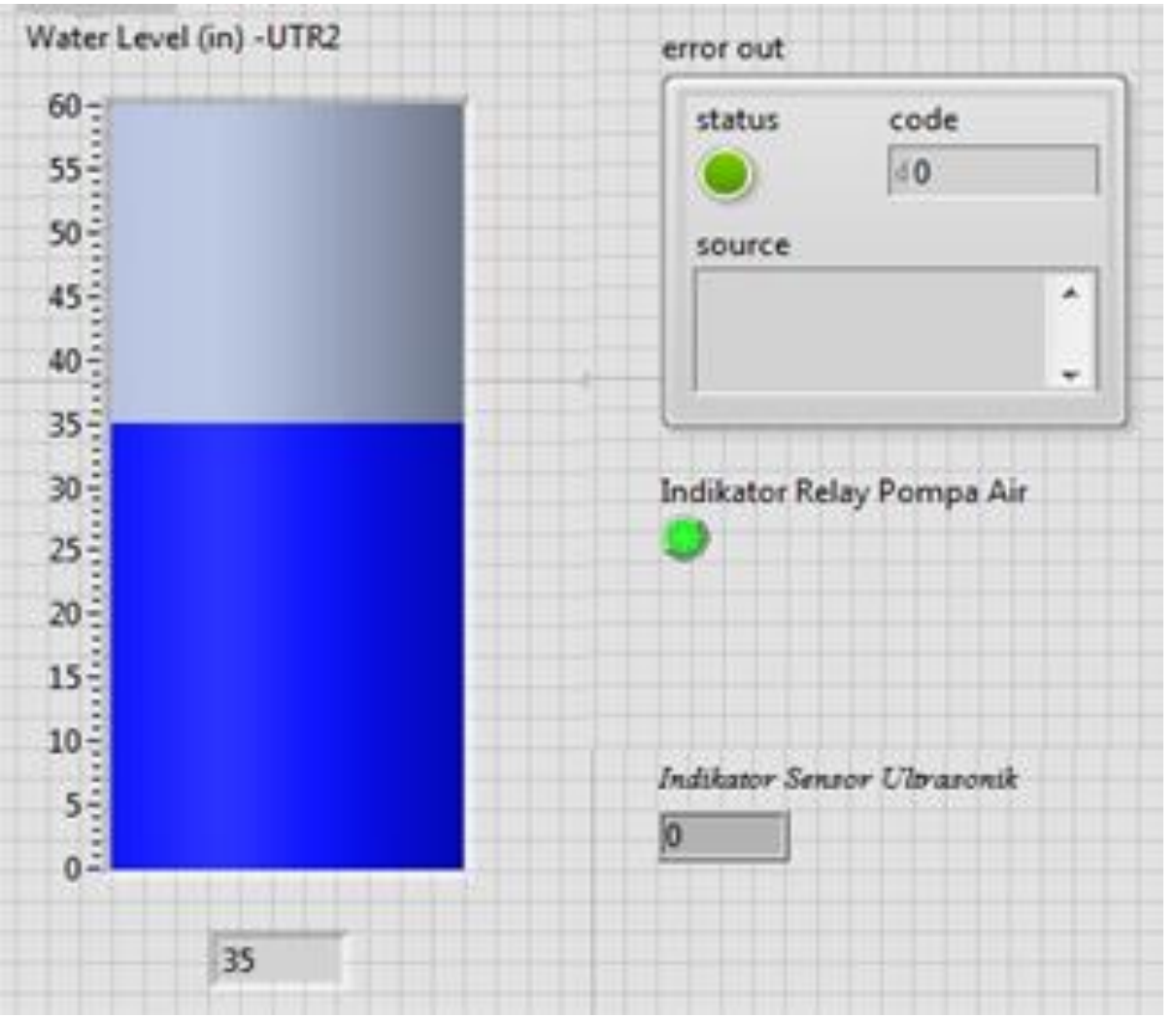

Figure 10. Water Pump Monitoring Control

Table 8. Testing System of Monitoring Water Levels, Relay, and Water Pump

\begin{tabular}{cccccc}
\hline No & \multicolumn{3}{c}{ Water Tank Monitoring } & Relay & Water \\
\cline { 2 - 4 } & $\begin{array}{c}\text { High-Scale } \\
\text { Tank }\end{array}$ & $\begin{array}{c}\text { Water Volume in } \\
\text { Tank (Liters) }\end{array}$ & $\begin{array}{c}\text { Ultrasonic Sensor } \\
\text { Indicator SRF 04 }\end{array}$ & $\begin{array}{c}\text { Relay } \\
\text { Indicator }\end{array}$ & $\begin{array}{c}\text { Pump } \\
\text { Condition }\end{array}$ \\
\hline 1 & 0 & 0 & 0 & Light up & ON \\
2 & 5 & 6.28 & 395 & Light up & ON \\
3 & 10 & 12.56 & 690 & Light up & ON \\
4 & 15 & 18.84 & 985 & Light up & ON \\
5 & 20 & 25.12 & 1280 & Light up & ON \\
6 & 25 & 31.4 & 1575 & Light up & ON \\
7 & 30 & 37.68 & 1870 & Light up & ON \\
8 & 35 & 43.96 & 2165 & ON \\
9 & 40 & 50.24 & 2460 & Light up & ON \\
10 & 45 & 56.52 & 2755 & Light up & ON \\
11 & 50 & 62.8 & 3150 & Light off & OFF \\
12 & 55 & 69.08 & 3550 & Light off & OFF \\
13 & 60 & 75.36 & 3995 & Light off & OFF \\
\hline
\end{tabular}

In Table 8, the testing results of monitoring water levels, relay and water pump displayed on LabView show that the system runs well. It can be concluded that the relay will start to function in the case of reaching minimum altitude in the level indicator turning on the water pump filling the tank with water until reaching pre-designated maximum water level condition. On the other hand, after reaching the maximum water level, the relay will interpret as OFF condition and deactivate the water pump stopping the water filling process in the tank.

\subsection{The Examination Results of System Monitoring}

The test described the monitoring of the whole system including the water height, turbidity, and the relay as a source of water pump controlled by $\mathrm{NI}$ myRIO being able to display 
all processes on the LabView software accessed by a laptop. The following picture displays overall process of monitoring height and water clarity on LabView.

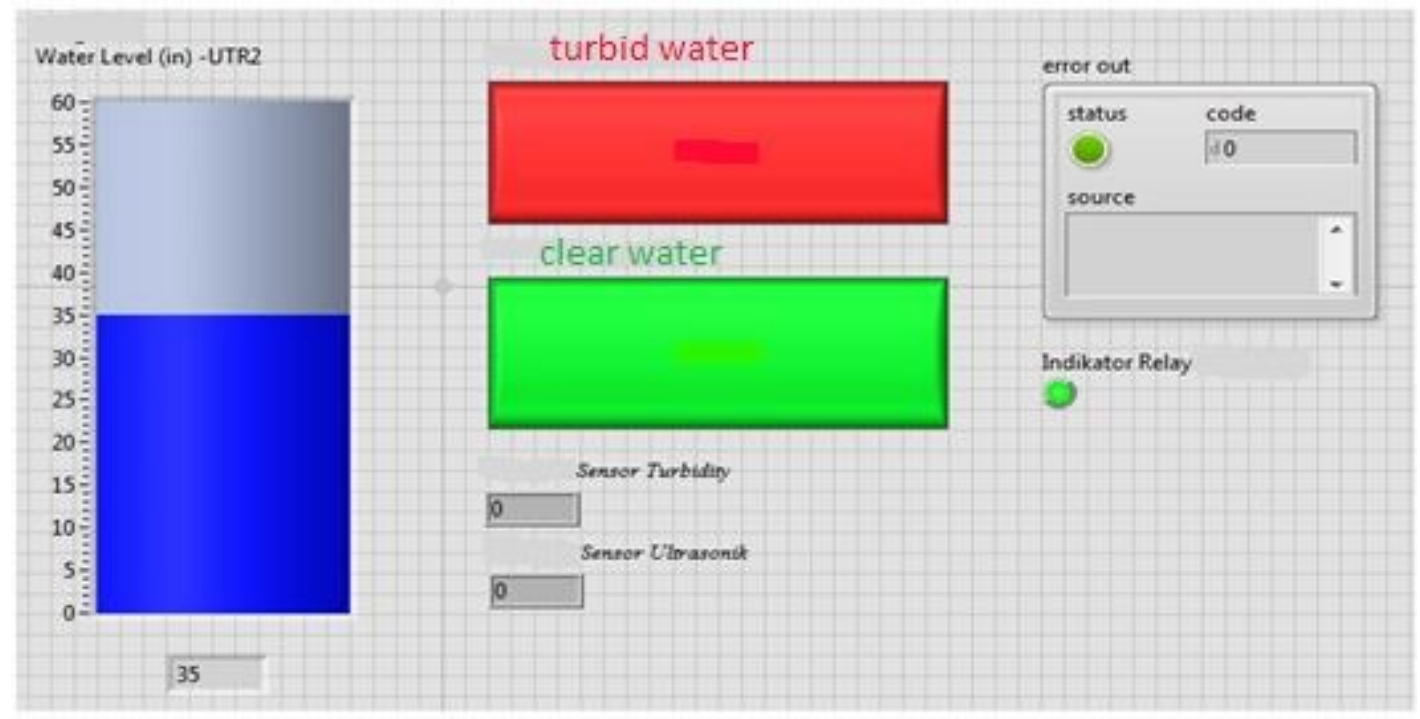

Figure 11. Monitoring View for the Whole System

Figure 11 displays the monitoring process of the whole system. This monitoring process can provide information on the overall system including automatic control of water filling on the relay and water turbidity level in the tank directly conveniently via a laptop utilizing LabView. This software, in addition, can display indicator values detected by the sensors.

\section{Conclusion}

Based on all conducted activities related to the preparation of a final report, started from library orientation, system planning, tool manufacturing and tool testing, the following conclusions can be drawn. The designed tools and systems are able to monitor water levels and water clarity displayed on a laptop utilizing LabView software controlled through NI myRIO. Hence, the user is able to monitor in real-time and obtain indicator values from the sensor reading.

Moreover, the automatic control relay on water pump is based on input of Ultrasonic sensors of SRF04 controlled by NI myRIO and will display all processes by LabView monitoring software on a laptop. The series of mechanical system or hard ware from NI MyRio to LabView software on a laptop is wirelessly monitored using Wi-Fi system in getting maximum convenience of the monitoring process. Additionally, keypad and LCD panel view will not be equipped due to the utilization of a laptop running LabView controlling NI myRIO simplifying the reading results on the system.

\section{References}

[1] Y. P. Wijaya, "Simulation Tank Volume Controlling Utilizing LabView and Arduino UNO," Science and Technology Industry Journals," Vol. 13, No. 1, Pp. 79-82, Feb. 2016.

[2] I. Setiawan, "Programmable Logic Controller (PLC) and Controlling System Design Technique," Yogyakarta: Andi Offset, 2006.

[3] D. P. Hariyanto and Anto Cuswanto, "Water Tank Filling Automation Based on AT8535 Microcontroller," 2010.

[4] "NI myRIO Project Essentials Guide," Electrical and Computer Engineering Department Rose-Hulman Institute of Technology.

[5] Budiono Eka, "Programmable Automation Controller Using LabView 7.1," Yogyakarta: Gava Media, 2009.

[6] Muhammad Muhsin, "Digital Electronic Theory and Solutions," Yogyakarta: Andi, 2004.

[7] A. K. Rahanda, M. T. Ir. Mochamad, Rochmad, and M. K. Eru, Puspita , S.T., "Coffee Machine Based on Microcontroller, "EEPIS, Surabaya.

[8] R. Bitter, T. Mohiuddin, and M. Nawrocki, "LabView Advanced Programming Techniques," Second Edition. CRC Press/Taylor \& Francis Group, 2007. 
[9] M. Budiyanto and A. Wijaya, "Introduction to Basics of PLC (First)," Yogyakarta: Gava Media, 2003.

[10] G. James, D. Witten, T. Hastie, and R. Tibshirani, "An Introduction to Statistical Learning," New York, NY: Springer New York, 2013. 